\title{
Genetic characterization of pomegranate (Punica granatum L.) genotypes by AFLP markers
}

\author{
Sezai Ercisli', Ebru Kafkas², Emine Orhan', Salih Kafkas³, Yildiz Dogan ${ }^{3}$ and Ahmet Esitken ${ }^{4}$ \\ 1 Department of Horticulture, Faculty of Agriculture, University of Ataturk, 25240 Erzurum - Turkey. \\ ${ }^{2}$ Subtropical Fruits Research and Experimental Center, University of Çukurova, 01330 Adana - Turkey. \\ ${ }^{3}$ Department of Horticulture, Faculty of Agriculture, University of Cukurova, 01330 Adana - Turkey. \\ ${ }^{4}$ Selcuk University Agricultural faculty Department of Horticulture 42031 Kampus - Konya - Turkey (Present address).
}

\begin{abstract}
The Coruh Valley, located in Northeastern Turkey, is one of the most important centers of diversity in pomegranate in Turkey. In this study, we attempted to characterize 19 promising pomegranate genotypes originating from the Coruh Valley in using fluorescent dye AFLP markers and capillary electrophoresis. Four AFLP primer combinations were used, generating a total of 297 fragments, 213 of which were polymorphic $(73.0 \%)$. Resolving powers of the AFLP primers ranged from 0.700 to 1.018 , with a total of 3.440, while polymorphism information contents ranged from 0.707 to 0.837 with an average of 0.764 . UPGMA clustering of the genotypes showed two major groups. Most of the fruit characteristics of the genotypes within the same group were variable. Therefore, the results showed that molecular characterization is necessary to get reliable relationships among pomegranate genotypes and AFLP markers can be used effectively in pomegranate.
\end{abstract}

Key terms: Genetic diversity, AFLP, Pomegranate.

\section{INTRODUCTION}

Pomegranate is presumed to have originated from the southern Caspian belt (Iran) and Northeast Turkey (Janick, 2007). The Mediterranean basin is an important center for diversification of the plant (Levin, 1994). The plant has high adaptive capacity and therefore, as a crop, is widely cultivated in tropical and subtropical areas, mainly in Mediterranean countries including Egypt, Morocco, Spain, Turkey and Tunisia. Turkey has a long history of pomegranate cultivation. Total pomegranate production in Turkey is about 100,000 metric tons per year (Durgac et al., 2008). Recently, pomegranate production has increased globally due to greater awareness of its health promoting phytonutritional content (Faria et al., 2007; Khan and Mukhtar, 2007; Malik et al., 2005). Indeed, pomegranate is one of the richest dietary sources of antioxidant phenolics and anthocyanins, and there is a wide variation among pomegranate genotypes in terms of these compounds (Ozgen et al., 2008).

In Turkey, the cultivation of pomegranate (Punica granatum L.) is mainly confined to semi-arid mild to temperate subtropical climates, including Mediterranean, Aegean and South East Anatolia regions (Ercisli et al., 2008). In addition, there are very special microclimate regions, such as the Coruh Valley, where pomegranate is abundant (Ercisli, 2004). However, little is known about the structure and the genetic diversity of the pomegranate germplasm in this area. With its rich biological diversity, the Coruh Valley is one of the 35 world hotspots of biodiversity pointed out by The World Conservation Union as the western section of the "Caucasus Ecosystem" (Anon, 2007). Its rich biological diversity, in particular for wild edible fruits including pomegranates, is a result of the extreme variation in climate within a very small area.
The pomegranates have routinely been characterized using morphological and biochemical markers (Mars and Marrakchi, 2008; Ozgen et al., 2008; Ozguven et al., 1997). These markers are valuable for pomegranate varietal group identification, but they show limited levels of detection of inter-varietal and intra-varietal polymorphisms on account of their environmental plasticity. DNA molecular markers provide a good and informative approach to estimate the genetic diversity and genetic relationships of horticultural plants. Recently, attention has been focused on the use of different molecular markers such as RAPD (randomly amplified polymorphic DNA), SSR (simple sequence repeat), SRAP (sequence-related amplified polymorphism), ISSR (inter-simple sequence repeat) and AFLP (amplified fragment length polymorphism) in different fruit species to determine genetic diversity and relationships among cultivars. Among them, RAPD has been extensively used in pomegranate because of its simplicity and low cost, but this marker system generates a limited number of polymorphism in pomegranate (Durgac et al., 2008; Ercisli et al., 2008; Sarkosh et al., 2006; Zamani et al. 2007). Yuan et al. (2007) and Jbir et al. (2008) characterized Chinese and Tunisian pomegranates using AFLP markers. They found that AFLP permitted the generation of a nearly unlimited number of markers that are reliable in differentiating pomegranate genotypes. In fact, among PCR-based molecular markers, AFLPs are highly reproducible multi-locus marker systems developed by Vos et al. (1995). High level of polymorphism and high degree of discriminative capacity are the main advantages of AFLPs for the analysis of closely related genotypes.

Although, the AFLP method has been used to identify genetic variability of many different plant species, the use of this powerful and reliable method in pomegranate is limited. The objective of this study is to characterize 19 pomegranate 
genotypes from the Coruh Valley in Turkey by AFLP markers, which will help breeders in parental selection in a pomegranate cultivar-breeding program.

\section{MATERIAL AND METHODS}

Plant material

The nineteen pomegranate genotypes had been previously selected from the Coruh Valley according to characteristics of yield, attractiveness of the fruit and degree of freedom from pests and diseases. The genotypes are found in diverse locations in the valley. Some important fruit characteristics of the genotypes are given in Table I.

\section{DNA extraction and AFLP analysis}

Genomic DNA was extracted from leaf tissue by the CTAB method of Doyle and Doyle (Doyle and Doyle, 1987) with minor modifications (Benjak et al., 2005; Kafkas et al., 2005). Concentration of extracted DNA was estimated by comparing band intensity with $\lambda$ DNA of known concentrations, after $0.8 \%$ agarose gel electrophoresis and ethidium bromide staining. DNA was diluted to $50 \mathrm{ng} \mu \mathrm{L}^{-1}$ for AFLP reactions.

Details of AFLP assay, adaptor and primer sequences, PCR conditions for preselective and selective amplifications, and selective primer designation were according to Vos et al. (1995) with minor modifications (Kafkas et al., 2008). Genomic DNA was restricted with EcoRI/MseI enzyme combination, and double-stranded adaptors specific to each site were ligated. Preselective amplification was carried out with primers complementary to the adaptors with an extra selective base on each primer (EcoRI-A/MseI-C). Selective amplification was performed with four primer combinations $\left(\mathrm{E}_{\mathrm{AGA}} / \mathrm{M}_{\mathrm{AGT}}, \mathrm{E}_{\mathrm{AGA}} /\right.$ $\mathrm{M}_{\mathrm{AGA}}, \mathrm{E}_{\mathrm{AGT}} / \mathrm{M}_{\mathrm{ACC}}$ and $\left.\mathrm{E}_{\mathrm{AGT}} / \mathrm{M}_{\mathrm{ATC}}\right)$. Fragments were resolved using capillary electrophoresis in an ABI 3130xl Genetic Analyzer [Applied Biosystems Inc., Foster City, Calif, (ABI)] with the data collection software 3.0 (ABI). AFLP fragment analysis was performed with GeneScanAnalysis Software 4.0 (ABI).

\section{Data analysis}

The ability of the most informative primer pairs to differentiate between the genotypes was assessed by calculating their resolving power (Rp) according to Prevost and Wilkinson (1999) using the formula $\mathrm{Rp}=\sum \mathrm{Ib}$, where $\mathrm{Ib}=1-(2 \times \mid 0.5-\mathrm{p}$ I) and $p$ is the proportion of the genotyps containing the I band. The polymorphism information content (PIC) of each marker was calculated using PIC $=1-\sum \mathrm{Pi}^{2}$ where $\mathrm{Pi}$ is the band frequency of the $i^{\text {th }}$ allele (SMITH et al. 1997). AFLP data were recorded as ' 1 ' for the presence of a band and ' 0 ' for its absence to generate a binary matrix. Only reproducible bands were scored for all the accessions tested. The data set was used to perform Principle Coordinate (PCoA) and cluster analyses using NTSYSpc 2.11V software (ROHLF 2004). Firstly, a similarity matrix was generated using Jaccard coefficients. This matrix was then used for PCoA. For cluster analysis, the

TABLE 1

Aril color, fruit weight, taste, seed hardness and peel firmness of 19 pomegranate genotypes

\begin{tabular}{|c|c|c|c|c|c|c|}
\hline Genotypes & Aril color & Fruit weight (g) & Taste & Seed hardness & Peel firmness & Coordinates \\
\hline APS 1 & Red & 457 & Sweet-Sour & Hard & Very firm & $4041 \mathrm{~N} 04140 \mathrm{E}$ \\
\hline APS 11 & Pink & 478 & Sweet-Sour & Soft & Very firm & 4047 N $04140 \mathrm{E}$ \\
\hline APS 12 & Pink & 261 & Sweet & Hard & Soft & 4047 N 04140 E \\
\hline APS 13 & Cream & 540 & Sweet-Sour & Hard & Moderate & 4047 N $04140 \mathrm{E}$ \\
\hline APS 21 & Red & 418 & Sweet-Sour & Semi-hard & Moderate & 4049 N $04137 \mathrm{E}$ \\
\hline APS 24 & Light Red & 510 & Sweet & Semi hard & Firm & $4049 \mathrm{~N} 04137 \mathrm{E}$ \\
\hline APS 28 & Pink & 379 & Sour & Hard & Firm & $4051 \mathrm{~N} 04141 \mathrm{E}$ \\
\hline APS 32 & Pink & 325 & Sour & Hard & Moderate & $4054 \mathrm{~N} 04144 \mathrm{E}$ \\
\hline APS 36 & Light Pink & 218 & Sweet & Semi hard & Firm & $4057 \mathrm{~N} 04145 \mathrm{E}$ \\
\hline APS 42 & Red & 475 & Sweet-Sour & Semi hard & Firm & $4045 \mathrm{~N} 04140 \mathrm{E}$ \\
\hline APS 48 & Pink & 391 & Sweet-Sour & Semi hard & Soft & 4049 N $04132 \mathrm{E}$ \\
\hline APS 49 & Light Red & 395 & Sweet & Semi hard & Firm & $4049 \mathrm{~N} 04132 \mathrm{E}$ \\
\hline APS 50 & Red & 399 & Sweet & Semi hard & Firm & $4050 \mathrm{~N} 04132 \mathrm{E}$ \\
\hline APS 56 & Red & 442 & Sweet-Sour & Soft & Very Firm & $4108 \mathrm{~N} 04200 \mathrm{E}$ \\
\hline APS 57 & Red & 369 & Sweet-Sour & Soft & Moderate & $4108 \mathrm{~N} 04200 \mathrm{E}$ \\
\hline APS 58 & Red & 365 & Sweet-Sour & Semi hard & Moderate & $4109 \mathrm{~N} 04158 \mathrm{E}$ \\
\hline APS 62 & Red & 518 & Sweet-Sour & Semi hard & Very firm & $4123 \mathrm{~N} 04164 \mathrm{E}$ \\
\hline APS 63 & Red & 306 & Sour & Semi hard & Very firm & $4130 \mathrm{~N} 04167 \mathrm{E}$ \\
\hline APS 64 & Dark Red & 380 & Sweet-Sour & Semi hard & Very firm & $4130 \mathrm{~N} 04167 \mathrm{E}$ \\
\hline
\end{tabular}


UPGMA (Unweighted Pair Group Method using Arithmetic Average) method was used to construct a dendrogram. The bootstrap values for the clusters were calculated with 1000 replicates using PAUP program (SWOFFORD 1998). The representativeness of dendrograms was evaluated by estimating the cophenetic correlation for the dendrogram and comparing it to the similarity matrix, using Mantel's matrix correspondence test (Mantel, 1967). The result of this test is a cophenetic correlation coefficient, $r$, indicating how well the dendrogram represents similarity data. For PCoA, the genotypes were plotted on the first three dimensions using the G3D procedure of SAS program (SAS 1990).

\section{RESULTS AND DISCUSSION}

The four primer combinations were used to characterize 19 selected promising pomegranate (Punica granatum) genotypes and results are shown in Table 2. In total, 297 bands were obtained using four primer combinations and among them 213 bands were polymorphic. A maximum of 60 polymorphic fragments was amplified with the $\mathrm{E}_{\mathrm{AGA}} / \mathrm{M}_{\mathrm{AGT}}$ primer pair, and a minimum of 42 polymorphic bands were scored with the $\mathrm{E}_{\mathrm{AGT}} / \mathrm{M}_{\mathrm{ATC}}$ primer pair. $73.0 \%$ polymorphism ratio was obtained from four primer combinations in this study. Therefore, AFLP seems an efficient method to examine the DNA polymorphisms in pomegranate. The number of markers scored in this study was greater than those reported for Iranian (Sarkosh et al., 2006; Zamani et al., 2007) and Turkish (Durgac et al., 2008) pomegranate cultivars, which were $57.3 \%, 57.0 \%$ and $22.0 \%$, respectively using RAPD markers. Therefore, it is obvious that AFLP marker system is more powerful than RAPD to discriminate pomegranate genotypes. Yuan et al. (2007) observed an average of $73.26 \%$ polymorphism among 85 Chinese pomegranate cultivars using eight AFLP primer pairs, which indicates a very similar polymorphism rate to that in our study. However, Jbir et al. (2008) obtained 94.7\% polymorphism using AFLP markers among 34 pomegranate cultivars sampled from 14 different locations in Tunisia. Although our samples originated from a small valley, the polymorphism rate can be comparable with the above results.

This richness in genetic diversity could be the result of long-term evolution, and represents the evolutionary potential of a species to adapt to various ambient pressures. The results from this study also showed that the Coruh Valley has rich pomegranate germplasm and it seems that selections had been done on these seedling materials. In fact, it is well known that the Coruh Valley is very close to the place of origin of the pomegranate.

The $\mathrm{Rp}$ values are also used to determine the ability of primers to differentiate pomegranate genotypes from Turkey, which ranged from $0.700\left(\mathrm{E}_{\mathrm{AGA}} / \mathrm{M}_{\mathrm{AGT}}\right)$ to $1.018\left(\mathrm{E}_{\mathrm{AGT}} / \mathrm{M}_{\mathrm{ATC}}\right)$ with a total of 3.440. However, $\mathrm{E}_{\mathrm{AGT}} / \mathrm{M}_{\mathrm{ATC}}$ primer combination had the lowest (0.707) polymorphism information content (PIC) (Table 2).

A dendrogram was obtained by the UPGMA method using the total number of AFLP bands (Fig. 1). There were two main groups in the dendrogram: Group 1 consisted of two genotypes namely APS-12 and APS-49. They were separated from the others with $100 \%$ of bootstrap replicates. This result indicated that these two genotypes are highly distinct from the others. However, the similarity index of two genotypes was only 0.33 .

The morphological fruit characteristics, except taste, of these two genotypes are highly variable. For example, APS-12 has pink colored arils, $261 \mathrm{~g}$ average fruit weight, hard seeds and soft peel, whereas APS-49 has light red colored arils, $395 \mathrm{~g}$ average fruit weight, semi hard seeds and firm peel (Table 1).

The rest of the 17 pomegranate genotypes formed Group 2 and the bootstrap replicates further separated Group 2 into two subgroups (Fig. 1): Subgroup 1 included APS-36, APS-48 and APS-64 genotypes, and they were separated from Subgroup 2 with $70 \%$ of the bootstrap replicates. Genetically APS-48 and APS-64 were found closer to each other with a 0.37 similarity index (Table 1). Among Subgroup 2, the closest genotypes were APS-1 and APS-11 with the highest similarity index (0.92), followed by APS-56 and APS-63 (0.81), and APS-13 and APS-28 (0.75) (Fig. 1).

Fruit characteristics of genotypes within Subgroup 1 are quite different from each other, except for seed hardiness (Table 1). In Subgroup 2, 14 pomegranate genotypes also had different fruit characteristics. APS-1 and APS-11 had a sweet-sour taste and very firm peels. However, aril color and seed hardness were highly variable between these two genotypes. In this subgroup, there were also genotypes that have pink, light pink, red, dark red, even cream aril color. Fruit weights were also highly variable (from $218 \mathrm{~g}$ to $518 \mathrm{~g}$ ) among the genotypes in this subgroup (Table 1 ).

TABLE 2

Total number of AFLP bands, percentage of polymorphic bands, resolving powers and polymorphism information contents in the DNA fingerprinting of pomegranate genotypes from Turkey

\begin{tabular}{cccccc}
\hline AFLP primer pairs & Total bands (no.) & $\begin{array}{c}\text { Polymorphic } \\
\text { bands (no.) }\end{array}$ & Polymorphism (\%) & Resolving power (Rp) & $\begin{array}{c}\text { Polymorphism information } \\
\text { content (PIC) }\end{array}$ \\
\hline $\mathrm{E}_{\mathrm{AGA}} / \mathrm{M}_{\mathrm{AGT}}$ & 65 & 60 & 92 & 0.700 & 0.837 \\
$\mathrm{E}_{\mathrm{AGA}} / \mathrm{M}_{\mathrm{AGA}}$ & 90 & 55 & 61 & 0.859 & 0.762 \\
$\mathrm{E}_{\mathrm{AGT}} / \mathrm{M}_{\mathrm{ACC}}$ & 82 & 56 & 68 & 0.863 & 0.750 \\
$\mathrm{E}_{\mathrm{AGT}} / \mathrm{M}_{\mathrm{ATC}}$ & 60 & 42 & 70 & 1.018 & 0.707 \\
Total & 297 & 213 & & 3.440 & 0.764 \\
Mean & 74.3 & 53.3 & 73 & 0.860 & \\
\hline
\end{tabular}




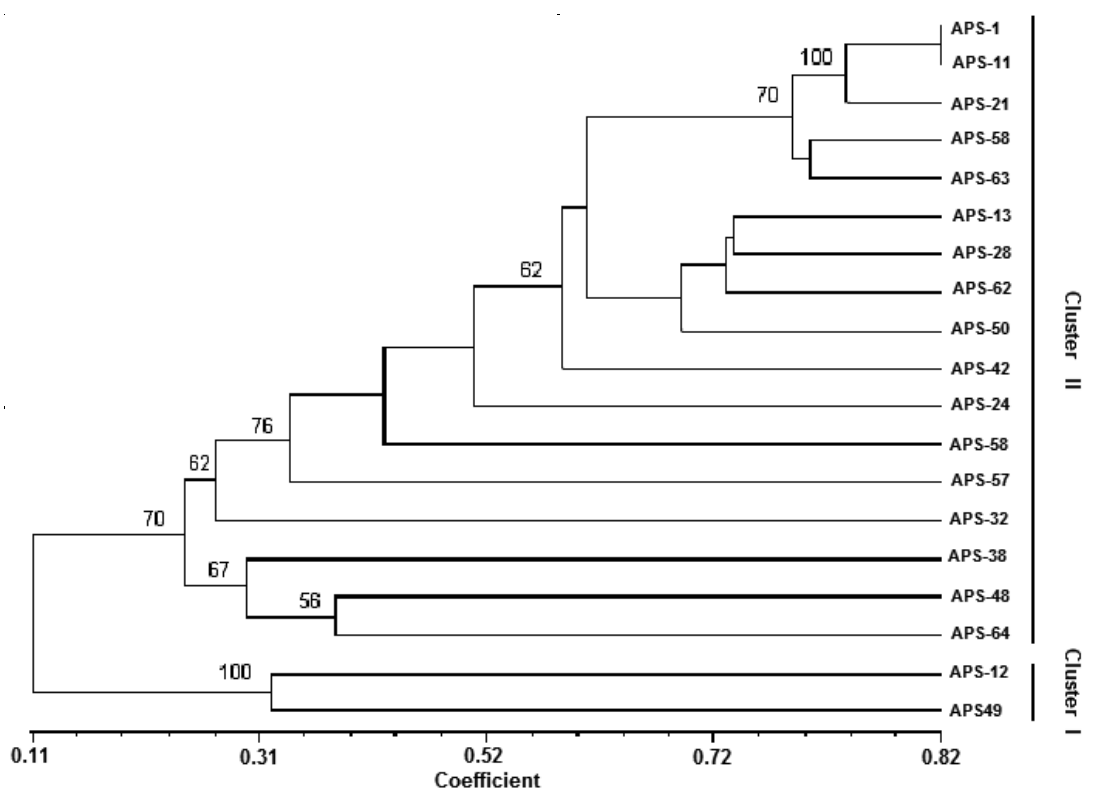

Figure 1. Dendrogram of 19 pomegranate genotypes from Coruh Valley in Turkey resulting from the unweighted pair-group method of arithmetic average cluster analysis based on Jaccard's similarity coefficient obtained from 297 AFLP markers. Only the nodes supported by $>50 \%$ bootstrap replicates are presented

It seems that there are no relationships between morphological and molecular data among pomegranate genotypes from the Coruh Valley. These discrepancies were previously reported by several authors working on pomegranate (Durgac et al., 2008; Sarkosh et al., 2006; Zamani et al., 2007). In most cases, based on the relative location of genotypes in the field (Figure 2), genotypes did not agree with those in clusters based on AFLP markers (Figure 1). For example, the closest genotypes APS-1 and APS-11 on AFLP dendrogram (Figure 1) were not found in similar places in the field (Figure 2). As well, the genotypes, APS-48, APS-49 and APS-50 were found very close to each other in the field (Figure 2) but on are far apart

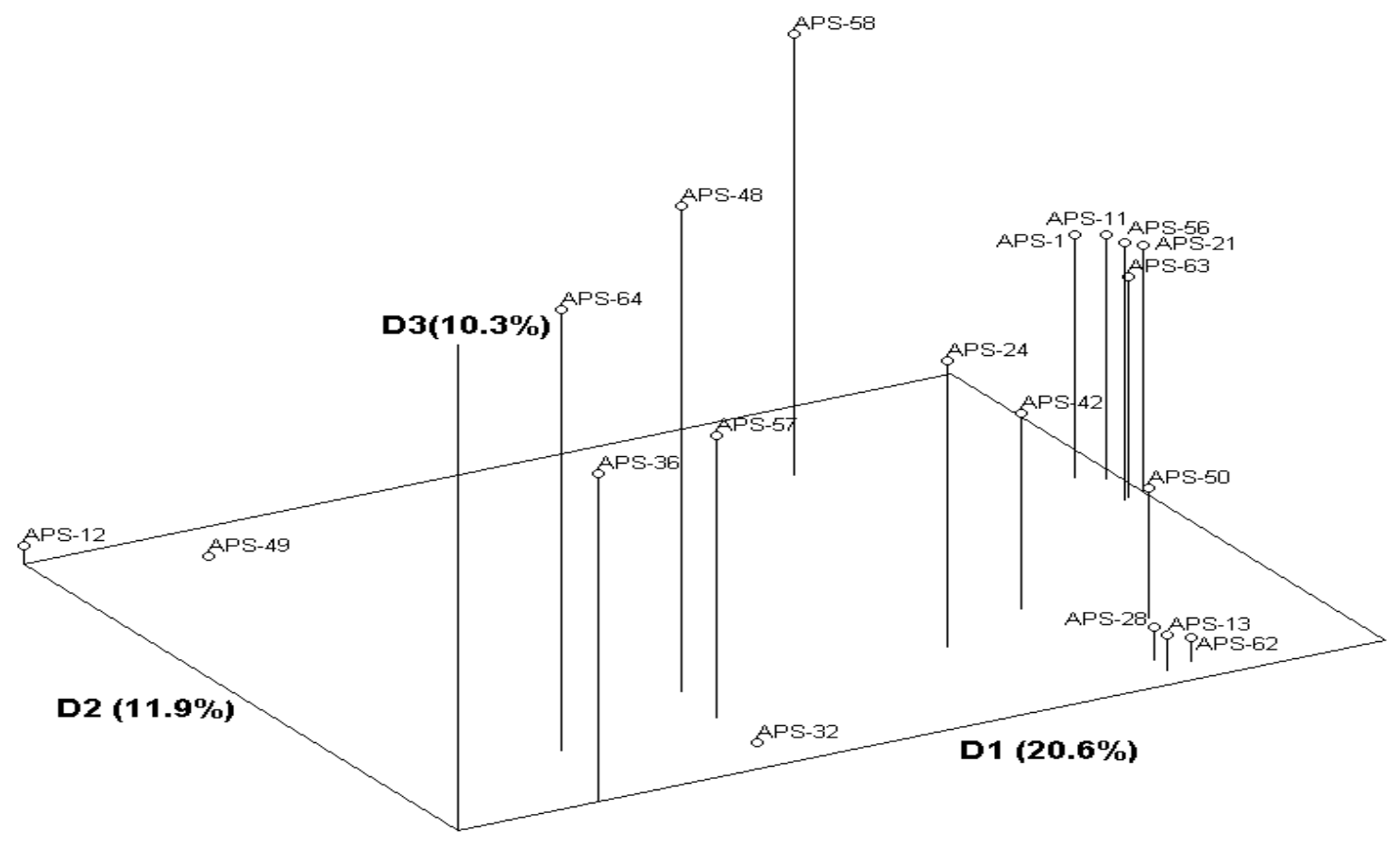

Figure 2. Principal coordinate analyses of 19 pomegranate genotypes from the Coruh Valley in Turkey resulting from analysis of 297 AFLP markers. 
on the dendrogram (Figure 1). The high level of phenotypic differences observed among pomegranate genotypes might be the result of environmental conditions, which greatly affect expression of quantitative traits. Jbir et al. (2008) stated that molecular markers provide more reliable results in pomegranate classification in comparison to morphological data. In addition, Zamani et al. (2007) stated that there is a poor correlation between fruit characteristics and RAPD data in pomegranate, and they found that the correlation coefficient between morphological and RAPD data was only $23 \%$. They also suggested that different marker systems, for instance, SSRs or AFLPs can be utilized to reveal genetic diversity among closely related pomegranate genotypes. In fact, Mars (2001) stated that the selection of pomegranate genotypes by farmers for production be mainly based on fruit characteristics. Therefore, only a small part of the genome encoding these traits is involved in empiric selection by farmers.

The Mantel test indicated that the cophenetic matrix of the dendrogram was very high $(r=0.93)$. Therefore, it can be concluded that the dendrogram provides a good representation of the similarity matrix.
Factor scores of the first three dimensions of PCoA for the AFLP data are shown in Fig. 2. In this analysis, the first three dimensions explain 20.6, 11.9 and $10.3 \%$ of the variation. The PcoA obtained from AFLP data supported the UPGMA dendrogram and the PcoA clearly separate Group I from Group II, indicating that they had high levels of molecular variation. The PcoA results are also revealed that APS 1 with APS 11 and APS56 with APS63 genotypes were the genetically closest genotypes (Fig. II).

In conclusion, Punica granatum genotypes sampled from diverse environments of the Coruh Valley displayed very rich genetic variations. A relatively large number of AFLPs were generated by four primer combinations and permitted surveying genetic diversity and relationships among pomegranate genotypes from the Coruh Valley. Therefore, the AFLP approach gives much more information about the genetic background of pomegranate genotypes used compared to fruit characteristics. As well, those parts of the genome amplified using AFLP primers might not be in genes that code for morphological characteristics (Zamani et al., 2007).

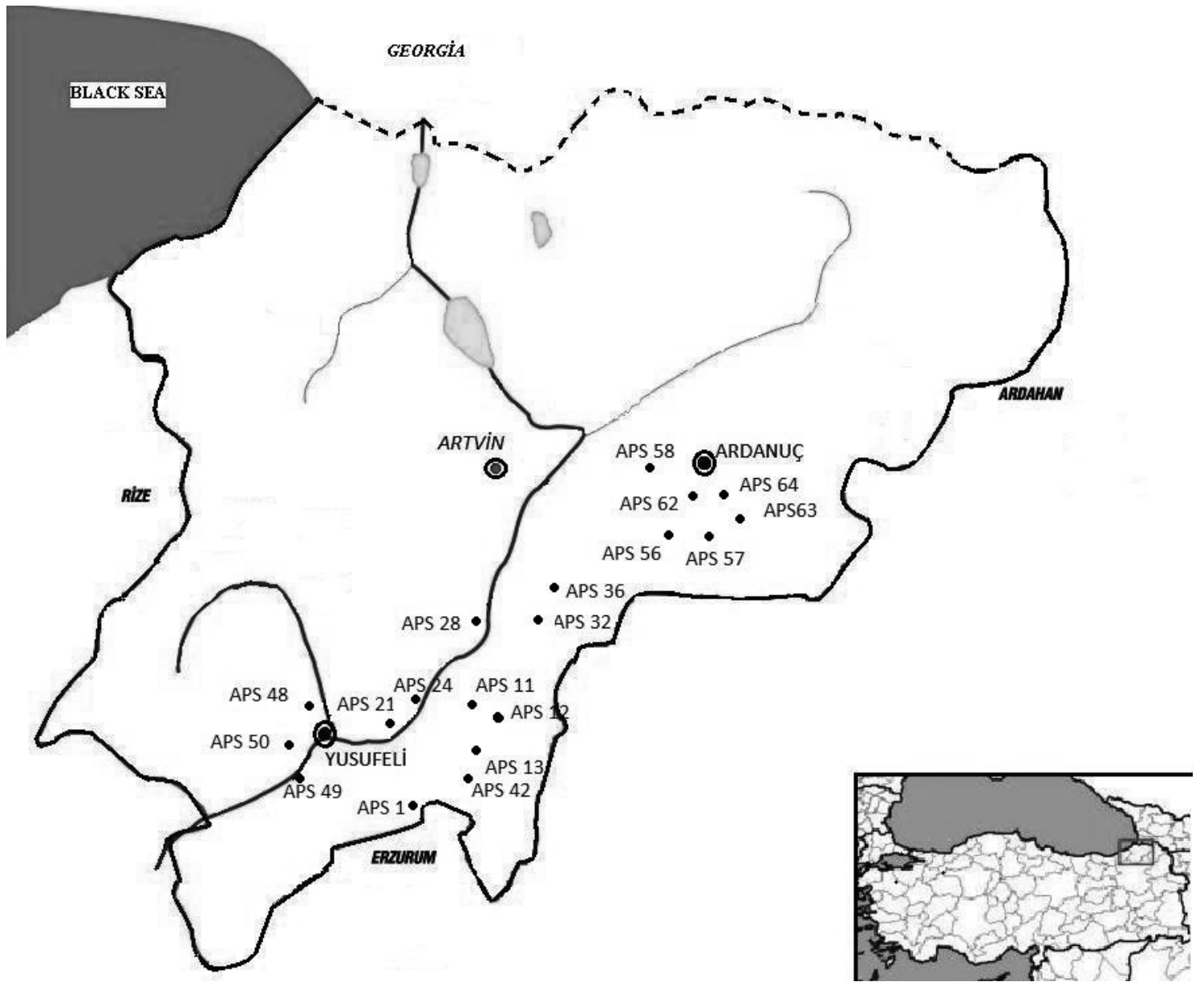

Figure 3. Relative locations of genotypes used in the study. 


\section{ACKNOWLEDGMENTS}

The authors express their gratitude to The Scientific and Technological Research Council of Turkey (TUBITAK) (Project No: TOVAG-105O636) for financial support.

\section{REFERENCES}

ANONYMOUS (2007) The World Conservation Union. www.iucn.org

BENJAK A, ERCISLI S, VOKURKA A, MALETIC E, PEJIC I (2005). Genetic relationships among grapevine cultivars native to Croatia, Greece and Turkey. Vitis 44:73-77.

DOYLE JJ, DOYLE JL (1987) A rapid isolation procedure for small quantities of fresh leaf tissue. Phytochem Bullet 19:11-15.

DURGAC C, OZGEN M, SIMSEK O, KACAR YA, KIYGA Y, CELEBI S, GUNDUZ K, SERCE S (2008) Molecular and pomological diversity among pomegranate (Punica granatum L.) cultivars in Eastern Mediterranean region of Turkey. Afr J Biotech 7:1294-1301.

ERCISLI S (2004) A short review of the fruit germplasm resources of Turkey. Genet Resour Crop Ev 51:419-435.

ERCISLI S, AGAR G, ORHAN E, YILDIRIM N AND HIZARCI Y (2007) Interspecific variability of RAPD and fatty acid composition of some pomegranate cultivars (Punica granatum L) growing in Southern Anatolia Region in Turkey. Biochem Syst Ecol 35:764-769.

FARIA A, MONTEIRO R, MATEUS N, AZAVEDO I, CALHAU C (2007) Effect of pomegranate (Punica granatum) juice intake on hepatic oxidative stress. Eur J Nutr 46:271-278.

JANICK J (2007) Fruits of the Bibles. HortScience 42:1072-1076.

JBIR R, HASNAOUI N, MARS M, MARRAKCHI M, TRIFI M (2008) Characterization of Tunisian pomegranate (Punica granatum L.) cultivars using amplified fragment length polymorphism analysisa. Sci Hortic 115:231-237.

KAFKAS S, OZKAN H, SUTYEMEZ M (2005) DNA polymorphism and assessment of genetic relationships in walnut genotypes based on AFLP and SAMPL markers. J Am Soc Hort Sci 130:585-590.

KAFKAS S, OZGEN M, DOGAN Y, OZCAN B, ERCISLI S, SERCE S (2008) Molecular characterization of mulberry accessions in Turkey by AFLP markers. J Am Soc Hort Sci 133:593-597.

KHAN N, MUKHTAR H (2007) Pomegranate fruit as a lung cancer chemopreventive agent. Drugs Fut 32:549-554.

LEVIN GM (1994) Pomegranate (Punica granatum L) plant genetic resources in Turkmenistan. Plant Genet Res News 97:31-36.
MALIK A, AFAQ F, SARFARAZ S, ADHAMI VM, SYED DN, MUKHTAR H (2005) Pomegranate fruit juice for chemoprevention and chemotherapy of prostate cancer. Proc Nat Acad Sci 102:14813-14818.

MANTEL N (1967) The detection of disease clustering and a generalized regression approach. Cancer Res 27:175-178.

MARS M (2001) Ressources ge'ne'tiques du grenadier (Punica granatum L.) en Tunisie : prospection, conservation et analyse de la diversite'. The ‘se de Doctorat es Sciences Naturelles. Faculte' des Sciences de Tunis, Universite' El Manar Tunis, Tunisie.

MARS M, MARRAKCHI M (1999) Diversity of pomegranate (Punica granatum L.) germplasm in Tunisia. Genet Resour Crop Ev 46:461467.

OZGEN M, DURGAC C, SERCE S, KAYA C (2008) Chemical and antioxidant properties of pomegranate cultivars grown in Mediterranean region of Turkey. Food Chem 111:703-706.

OZGUVEN AI, TATLI H, COSKUN M, DASGAN Y (1997) Mediterranean and Aegean pomegranate varieties under ecological conditions of Adana, Turkey. Acta Hort 441:345-348.

PREVOST A, WILKINSON MJ (1999) A new system of comparing PCR primers applied to ISSR fingerprinting of potato cultivars. Theor Appl Genet 98:107-112.

ROHLF FJ (2004) NTSYS-pc numerical taxonomy and multivariate analysis system. Version 2.11V. Exeter software, Setauket, New York.

SARKOSH A, ZAMANI Z, FATAHI R, EBADI A (2006) RAPD markers reveal polymorphism among some Iranian pomegranate genotypes. Sci Hortic 111:24-29.

SAS (1990) SAS users guide; SAS/STAT, version 6. SAS Inst. Inc., Cary, N.C.SMITH JSC, CHIN ECL, SHU H, SMITH OS, WALL SJ, SENIOR ML, MITCHELL SE, KRESOVICH S, ZIEGLE J (1997) An evaluation of the utility of SSR loci as molecular markers in maize (Zea mays L.): comparisons with data from RFLPs and pedigree. Theor Appl Genet 95:163-173.

SWOFFORD DL (1998) PAUP: Phylogenetic analysis using parsimony (and other methods). Version 4. Sineauer Assoc., Sunderland, Mass.

VOS $\mathrm{P}$, HOGERS L, BLEEKER $\mathrm{M}$, VAN DE LEE T, HORNES $\mathrm{M}$, FRIJTERS A, POT J, PELEMAN J, KUIPER M, ZABEAU M (1995) AFLP: A new technique for DNA fingerprinting. Nucleic Acids Res 23:4407-4414.

YUAN Z, YİN Y, QU J, ZHU L, Lİ Y (2007) Population genetic diversity in Chinese pomegranate (Punica granatum L.) cultivars revealed by fuorescent-AFLP markers. J Genet Genom 34:1061-1071

ZAMANI Z, SARKHOSH A, FATAHI R, EBADI A (2007) Genetic relationships among pomegranate genotypes studied by fruit characteristics and RAPD markers. J Hort Sci Biotech 82:11-18. 